Editorial

\title{
Warming up the old dishes
}

\section{Abstract}

Old dishes are not necessarily the bad dishes. Creativity by nature is not easily accepted at the very beginning. Warming up the old dishes is like rediscovering the unforgettable pieces of good old sciences.

Keywords: rediscover
Volume 2 Issue 2 - 2015

\section{Youhe Gao}

Department of Biochemistry and Molecular Biology, Beijing Normal University, China

Correspondence: Youhe Gao, Department of Biochemistry and Molecular Biology, Beijing Normal University, Gene Engineering and Biotechnology Beijing Key Laboratory, Beijing, 100875, P. R. of China, Tel 86I058804382,

Email gaoyouhe@gaoyouhe

Received: March 24, 2015 | Published: March 28, 2015

\section{Editorial}

I don't know how many papers are produced each day. People are looking at what is under the spot light because of information overflow. Most of the other works are grossly ignored. As the information is produced faster, this trend may become worse. When you encounter huge amount of information, when you have very limited time to decide what is good what is not, the chance of losing the good ones is big. We think we have search engines. We believe that all the useful information will jump out automatically. Actually the information is exploding. The information even growing faster than the search engines can fully digest and selectively present all the useful works to the persons who need and want that information. That is a big waste of the research resources in the world. Grant is scarce and valuable. The good works produced from the grant is invaluable. The person who appreciates the value of the work is the author him/herself. But the author cannot publish the same work twice. What if we know there is real good piece of gem?
This is what this journal is created for. This is what the opinion category created for. You can always come to us to warm up your good old dishes. That is the way we show our respect to gems left in the dusts in sciences. Our journal may not be in the spot light. But we can still contribute to science in our own special way.

\section{Acknowledgements}

This work was supported by the National Basic Research Program of China (2012CB517606, 2013CB530805), the Key Basic Research Program of China (No. 2013FY114100), and the 111 Project (B08007).

\section{Conflict of interest}

The author declares no conflict of interest. 